\title{
Sugar relationships: sexo, afeto e consumo na África do Sul e no Brasil
}

\author{
Thais Henriques Tiriba' (iD) 0000-0002-7438-3724 \\ 'Universidade de São Paulo, Programa de Pós-Graduação em Antropologia Social, São \\ Paulo, SP, Brasil.05508-010-ppgas@usp.br
}

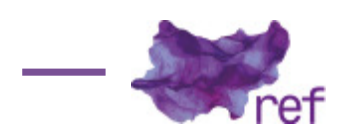

Resumo: Neste artigo, analiso os valores atribuídos na África do Sul a relacionamentos afetivo-sexuais chamados sugar relationships que são estabelecidos por meio da mediação de páginas na internete aplicativos para este fim. Trata-se de um arranjo intergeracional no qual homens de mais recursos, conhecidos como sugar daddies ou blessers, engajam-se em intercâmbios afetivo-sexuais-materiais com mulheres mais jovens. Apresento um levantamento da maneira como sugar relationships vêm sendo tratados na grande mídia em paralelo aos esforços de parte da produção local em desafiar os regimes de moralidade que informam os ânimos a respeito desses arranjos. Ao buscar as interconexões entre Brasil e África do Sul, aponto para as maneiras segundo as quais a produção brasileira vem lidando com debates e contextos similares.

Palavras-chave: sexualidade; África do Sul; marcadores sociais da diferença; mídias digitais; economias sexuais.

Sugar Relationships: Sex, Affection and Consumption in South Africa and Brazil

Abstract: In this article, I analyze the values attributed to affective-sexual relationships in South Africa, known as sugar relationships, which are established through the mediation of websites and applications. It is an intergenerational arrangement, in which men of more resources, known as sugar daddies or blessers, engage in affective-sexual-material exchanges with younger women. I present an overview of how sugar relationships have been depicted in mainstream media alongside with efforts by the local academic production to challenge the morality regimes that inform the public's dispositions concerning these arrangements. In searching for the interconnections between Brazil and South Africa, I point to the ways according to which Brazilian academic production has been dealing with similar debates and contexts.

Keywords: Sexuality; South Africa; Social Markers of Difference; Digital Media; Sexual Economies.

\section{Introdução}

Mas o que é um blesser?' Ele é uma nova versão do sugar daddy, exceto que seu poder de compra o coloca em um pedestal muito mais alto, dando a ele um status divino. E quando você namora um, é dito que você literalmente sente que sua vida foi abençoada. Fiscalmente, pelo menos (Nelly SHAMASE, 2016).

Em meados de 2016, a hashtag \#AntiBlessers era trending topic no Twitter ${ }^{2}$ sul-africano. 0 tema é fonte de calorosos debates promovidos tanto pela opinião pública quanto pelas autoridades. O termo blesser foi cunhado e disseminado nas mídias sociais nos últimos anos, especialmente pelo aplicativo de compartilhamento de fotos Instagram. ${ }^{3}$ No mundo de língua inglesa, a hashtag

\footnotetext{
' As traduções dos trechos citados foram realizadas por mim.

${ }^{2}$ Twitter é uma rede social de mais de 280 milhões de usuários que lhes permite postar textos de até 280 caracteres. Trendingtopics ou "Assuntos do momento" é uma lista em tempo real dos marcadores, também conhecidos por hashtags (\#), mais postadas por usuários em todo o mundo.

${ }^{3}$ Instagram é uma rede social de compartilhamento de fotos e vídeos lançada em 2010 que conta com 800 milhões de usuários.
} 
\#blessed é comumente utilizada por usuários/as ao lado de postagens de fotos de suas famílias, de viagens ou de momentos com amigos. Seu uso implica a expressão de um sentimento de sorte, de gratidão. Em tradução livre, as pessoas a utilizam quando querem se dizer \#abençoadas.

Na África do Sul, essa mesma hashtag tomou caminhos um pouco diferentes, uma vez que passou a ser usada, também no Instagram, por jovens mulheres que postavam fotos de presentes de luxo que lhes tinham sido dados por seus parceiros (Kate LAMBLE, 2016). Ao se dizerem \#blessed por possuírem tais itens, outros/as usuários/as passaram a confrontar essas postagens, perguntando quem estaria dando a elas tais itens de luxo. Quem seriam os blessers, os abençoadores, por trás dos presentes que essas atraentes jovens mulheres exibiam nas redes sociais?

Colocado de forma sintética, blessers, sugar daddies ou papa bears são os nomes dados a homens que se engajam em relacionamentos com mulheres mais jovens e com menos recursos. A compreensão usual acerca da relação de sugar daddies com sugar babies é que os primeiros fariam uso de seu maior status social para oferecer a elas bens materiais em troca de favores sexuais. Na mídia, no senso comum e em parte da produção acadêmica, esses relacionamentos, às vezes chamados de relacionamentos intergeracionais transacionais, são lidos em termos altamente morais: sugar daddies são predadores sexuais e, sugar babies, ou blessees, vítimas desses homens.

Enquanto boa parte da sociedade condena esse gênero de relacionamento que, como apontarei adiante, jamais se tratou de arranjo incomum, novas ferramentas tecnológicas não apenas permitem o compartilhamento de tais imagens ditas ostensivas, mas também facilitam o encontro de homens e mulheres que desejam se engajar nessas trocas. Aplicativos comuns de relacionamento como o Tinder, ${ }^{4}$ tanto na Cidade do Cabo quanto em Joanesburgo, estão repletos de perfis de homens que se referem a si como sugar daddies ou blessers, anunciando estarem em busca de uma jovem mulher atraente para "mimar" [to spoil]. Além dos populares aplicativos de relacionamento, estão disponíveis no mercado ferramentas específicas para o encontro de sugar relationships, como às vezes são chamados na África do Sul. Exemplos são as páginas Blesserfinder, o site Blessers and Blessees e a vertente sul-africana da conhecida plataforma internacional SeekingArrangement. ${ }^{5}$

O pânico moral que esse encontro desperta não é, naturalmente, especificidade sulafricana. Em 2017, o governo belga procurava processar o site Rich meet beautiful. Este se dizia um dating site para sugar daddies e sugar babies e anunciava seus serviços colocando grandes pôsteres nas saídas dos campi universitários do país (Daniel BOFFEY, 2017). Devido a seus serviços e ao slogan "Improve your lifestyle. Get a sugar daddy", os críticos diziam que o site estaria encorajando a prostituição por se fazer valer da insegurança financeira das jovens.

De forma similar, o mesmo pânico moral acomete as autoridades e o senso comum no Reino Unido, onde a plataforma SeekingArrangement diz ter em sua base de cadastro mais de um quarto de milhão de estudantes no país. Também em 2017, reportagens sobre o envolvimento de estudantes na chamada "indústria do sexo" chocaram a sociedade britânica. Os levantamentos apontavam que um/a em cada cinco estudantes no país já teria considerado se envolver na indústria e um/a em cada vinte já o tinha feito em alguma ocasião (Rick KELSEY, 2016). No Brasil, essa mesma plataforma conta com página em português e atua desde 2016 . No ano anterior já estava no ar o site nacional Meu Patrocínio, que oferece o serviço de busca por arranjos similares.

Neste artigo, parto das discussões acerca dos chamados sugar relationships na África do Sul para indagar de que modo as produções acadêmicas na África do Sul, e também no Brasil, vêm navegando nas discussões sobre intercâmbios econômicos e sexuais (sobre os olhares cruzados para o sul e para um balanço da produção brasileira em países da África, ver o artigo de Laura MOUTINHO; Wilson TRAJANO FILHO; Andrea LOBO, 2017).

Na primeira parte do artigo, apresento um levantamento da maneira como sugar relationships vêm sendo tratados na grande mídia em paralelo aos esforços de parte da produção local em desafiar os regimes de moralidade que informam os ânimos a respeito desses arranjos.

Na segunda parte, busco investir nas interconexões entre Brasil e África do Sul, apontando para as maneiras segundo as quais a produção brasileira vem lidando com debates e contextos similares.

Assim como em Pedro Lopes (2019 [nesta Seção Temática]), não se trata de um texto comparativo ponto a ponto. Busco, assim como o autor que delineia as aproximações entre África do Sul e Brasil na temática da deficiência, somar-me aos esforços de também contribuir para uma virada ao Sul (Turning South, como elaborado por Zethu MATEBENI, 2017), e apontar para caminhos profícuos que o encontro dessas produções sobre intercâmbios econômicos e sexuais pode proporcionar. ${ }^{6}$

\footnotetext{
${ }^{4}$ Tinder é um aplicativo para smartphones que coloca usuários em contato a partir de suas geolocalizações para encontros românticos.

${ }^{5}$ A internet é particularmente cara na África do Sul, entretanto, todos têm aparelho celular no qual inserem créditos (airtime e data) de modo que, mesmo em regiões mais pobres, o celular é o meio de acesso ao mundo virtual.

${ }^{6}$ Sobre a perspectiva comparada vide, nesta Seção Temática, o artigo de Esmeralda Mariano e Denise Dias Barros, e a apresentação de Laura Moutinho.
} 


\section{Sexo, afeto e consumo na "nova" África do Sul}

Na primeira visita que fiz ao país, chamou-me atenção a frequência com a qual relacionamentos sugar eram mencionados, tanto em conversas informais, quanto em debates sobre gênero e sexualidade que presenciei na Cidade do Cabo, no âmbito da University of Cape Town e da Stellenbosch University. ${ }^{7}$

Em levantamento de artigos jornalísticos publicados nos últimos anos, pude perceber que o termo blesser é amplamente conhecido e utilizado tanto em publicações de tipo tabloide, quanto em jornais independentes e/ou entendidos como mais respeitáveis. Para ter uma noção mais precisa desse alcance, realizei buscas pelos termos "sugar daddy" e "blesser" nas páginas de quatro jornais sul-africanos de língua inglesa: The Sunday Times, o jornal semanal de maior circulação no país, Mail \& Guardian, jornal semanal independente, The Citizen, tabloide de distribuição nacional e The South African, um site de notícias com crescente número de leitores.

Encontrei a expressão "sugar daddy syndrome" ou "blesser phenomenon" em um número de reportagens jornalísticas que tratavam da prática segundo a qual "homens mais velhos seduzem meninas jovens - ou grupos de meninas - com crédito para celular, roupas, sapatos, joias e celulares em troca de sexo, com um único blesser supostamente tendo infectado 15 garotas por semana" (Dave SAVIDES, 2016). Em artigo do jornal sul-africano Sunday Times, o país aparece como líder mundial nas buscas on-line pelo termo "sugar daddy sites" (THE SUNDAY TIMES, 2018).

O termo já foi usado para acusar o atual presidente, Cyril Ramaphosa, e seu predecessor, Jacob Zuma (Mzilikazi WA AFRIKA, 2017). Um número grande de celebridades e de políticos também já foi alvo de acusações. Nessas reportagens, a prática está intimamente associada a um aumento no contágio de HIV/AIDS em jovens mulheres e um aumento nos casos de gravidez na adolescência.

A mídia, a opinião pública, grupos políticos e grupos religiosos se organizam para denunciar e combater esses arranjos afetivo-sexuais. Dentro deste último, líderes de igrejas de várias denominações cristãs denunciam o abuso da palavra "blesser". Eles urgem para que se recapture a palavra e "a levem de volta aos lugares de adoração".

"Não tenham relacionamentos com sugar daddies e blessers", advertiu a ANC Youth League ${ }^{8}$ em comunicado. Uma membra do comitê executivo da juventude do partido que governa o país a nível nacional, Jane Khoza, diz que jovens meninas devem "parar de buscar atalhos" nos namoros com blessers. A coordenadora da liga de mulheres do mesmo partido, Precious Banda, coloca que:

Se esse homem banca seu estilo de vida, suas opções são limitadas pois o homem é o financiador. Existem oportunidades disponíveis, como educação superior gratuita, e nós estamos dizendo que as mulheres jovens devem se educar e se envolver em atividades econômicas (In Zingisa MVUMVU, 2018).

Em entrevista, a presidente da fundação King Goodwill Zwelethini's Bayede, Rhana Naicker, diz: "meu apelo é para que as mulheres se ergam, assumam o papel de modelos e usem suas vozes para fazer a diferença em programas de regeneração moral que vão ensinar jovens meninas a se respeitarem e a respeitarem seu valor" (SAVIDES, 2016). Colocações similares em artigos de opinião são recorrentes, como no trecho a seguir:

O estilo de vida blesser-blessee recentemente ganhou fama. Realmente, é vergonhoso, repugnante e deplorável. É simplesmente prostituição de luxo, tudo para ganho temporário. 0 que nossa sociedade se tornou? Jovens mulheres estão se rebaixando a ponto de serem usadas como mercadorias intercambiáveis. Tudo isso por bolsas, mechas de cabelo e champagne (Kekeletso NAKELI-DHLIWAYO, 2016).

Sobre uma sociedade que valorizaria a ostentação de itens de luxo postados em mídias sociais, em um artigo de opinião em um conhecido jornal sul-africano, a autora se pergunta: "Nós nos tornamos tão escravizados pelo dinheiro, pelas aparências, por coisas materiais e pela necessidade de projetar realidades falsas que estamos dispostos a abrir mão de nossa autoestima e descartar nossa fibra moral?" (SHAMASE, 2016).

\footnotetext{
7 Os levantamentos e observações realizados para a elaboração deste artigo se deram através de duas estadias no país (mar./abr. 2017 e fev./mar./abr. 2018) no contexto do projeto PROÁFRICA/CNPq - "A vizinhança nas entrelinhas: alianças e conflitos, trocas (des)iguais e cooperação entre Moçambique e África do Sul", coordenado por Laura Moutinho. Integraram a pesquisa: Brigitte Bagnol, Esmeralda Mariano, José Ricardo Ayres, Lilia Schwarcz, Paulo Sérgio da Costa Neves, Pedro Lopes e Rita Simone Liberato, tendo sido incorporadas ao longo do processo as pesquisadoras Denise Dias Barros, Carla Braga, Solange Rocha, Gabriela Calazans, Isabel Noronha e Susan Holland-Muter. Essas discussões estão ainda alinhadas com meu projeto de doutoramento, intitulado "Blessers e Blessees: sexo afeto e consumo na 'nova' África do Sul", em andamento junto ao Programa de Pós-Graduação em Antropologia Social da Universidade de São Paulo (PPGAS/USP), orientado por Laura Moutinho e que conta com apoio da Fundação de Amparo à Pesquisa do Estado de São Paulo (FAPESP).

${ }^{8}$ O African National Congress (ANC) é um partido político fundado em 1912. É o principal partido da África do Sul desde o fim do apartheid e tem Nelson Mandela como figura mais influente. O ANC governa o país a nível nacional desde 1994, com o fim do regime segregacionista. A ANC Youth League é a ala da juventude do partido. A Youth League mantém forte atuação política desde sua fundação, em 1944.
} 
Alguns estudos na África do Sul (Lucie CLUVER et al., 2013; 2016) vêm mostrando que adolescentes cujas unidades domésticas recebiam auxílio financeiro estatal direcionado às crianças eram dois terços menos propensas a ter um namorado muito mais velho em contrapartida a jovens de lares que não recebiam o benefício. Esses sistemas poderiam, as pesquisadoras argumentam, reduzir substancialmente a escolha insegura de parceiros por meninas adolescentes (SAPA, 2013). Curiosamente, esses resultados não estão em desacordo com a colocação do portavoz da controversa plataforma sul-africana Blesserfinder. Ditshego diz estar confiante que haverá demanda para os serviços da empresa. A demanda continuará a existir, ele defende, até que o governo dê passos significativos para corrigir os índices de pobreza e desigualdade na África do Sul (Sarah ADAMS, 2016).

De todo modo, a moralidade da prática aparece bem mais frequentemente como pauta. Blessers "atacando" jovens meninas, ou jovens meninas "se vendendo" por champanhe e mechas de cabelo, como são frequentemente compreendidas essas trocas.

Tomo aqui a definição de moral operada por Didier FASSIN (2008): refere-se "à crença humana na possibilidade de se distinguir o certo do errado e a necessidade de se agir a favor do bem e contra o mal" (p. 334). Os contextos de trocas afetivas-sexuais-materiais sobre os quais se debruça a produção sul-africana (e também a brasileira) remetem à reivindicação de uma antropologia da moral, como sugerida por esse autor.

Tratar-se-ia não de uma antropologia que propusesse um código de boa conduta ou um guia, mas uma que ajudasse a

entender os princípios e práticas avaliativos operando no mundo social, os debates que eles despertam, os processos pelos quais eles são implementados, as justificativas que são dadas para explicar discrepâncias observadas entre o que deveria ser e o que de fato é (FASSIN, 2008, p. 334-335).

Parece-se estar diante de cenários que acolhem essa discussão. É necessário, todavia, localizar as especificidades desse fenômeno no país. A África do Sul enfrenta hoje desafios sociais e políticos no pós-apartheid, sistema cuja manutenção dependeu grandemente da gestão da sexualidade a partir de critérios raciais (Laura MOUTINHO, 2004a; 2004b; MOUTINHO et al., 2010). Tratou-se de um regime rígido de segregação que foi elaborado de forma a impedir 0 desenvolvimento de empatia, solidariedade e identificação com outros racialmente distintos. África do Sul pós-apartheid é um lugar onde:

[C]otidianamente, uma verdadeira batalha de gestos, vocabulários, sentidos e (re)posicionamentos é vivida. Os ressentimentos e a exclusão (que não são em absoluto categorias auto-evidentes) partilhados por alguns criam novas comunidades de sentidos e adesões, mas igualmente reposicionam indivíduos em novas (e antigas) situações de assimetria e hierarquia, a partir dos sentidos atribuídos a marcadores sociais como raça, língua, gênero e orientação sexual. Mais do que especificar ou construir sujeitos em certos contextos (mais ou menos desejáveis nos mercados dos afetos e prazeres, das amizades, do trabalho) ou revelar as assimetrias de poder que se constroem a partir da complexa e sutil operação dessas clivagens, vê-se na tessitura do cotidiano disputas acerca da construção do "nós" e do "outro" (MOUTINHO et al., 2010, p. 173).

Mark HUNTER (2012) argumenta que, no pós-apartheid, o sexo, o amor e a intimidade sofreram complexas transformações, informadas, por um lado, pelo histórico dos regimes colonial e do segregacionista e, por outro lado, pela política econômica adotada após a virada democrática.

AÁfrica do Sul é um país de 49 milhões de habitantes. Em termos raciais, $79 \%$ da população é black, $9 \%$ é white, $9 \%$ é coloured e $3 \%$ é indian 9 (Robert MORREL et al., 2012). Um dos países mais desiguais do mundo, a África do Sul conta com taxas muito altas de desemprego (Jason HICKEL, 2015). A renda de lares black corresponde a 16\% daquela de lares white, e $61,9 \%$ de todos os blacks sul-africanos vivem abaixo da linha da pobreza, número que sobe para $79,1 \%$ na zona rural.

Hickel (2015) afirma que a liberalização do mercado, política pela qual o African National Congress (ANC) ${ }^{10}$ optou na transição para o regime democrático, não apenas falhou em propiciar a prosperidade que seus proponentes asseguravam, mas também levou a uma deterioração da situação, que teria resultado em um sentimento agudo de crise entre sul-africanos, cujas esperanças na virada democrática teriam sido, ao longo dos anos, meticulosamente comprometidas.

Para alguns autores, as consequências da neoliberalização têm sido experienciadas como "crise de reprodução social" (HUNTER, 2012; HICKEL, 2015). As quedas nas taxas de casamento seriam evidência desse cenário na África do Sul, um dos países onde se observam as quedas mais drásticas (HUNTER, 2016).

9 Seguindo Moutinho (2015), mantenho ao longo do texto as categorias raciais no idioma original, com o objetivo de evitar transposição de sentido entre diferentes contextos.

${ }^{10} \mathrm{O}$ ANC é o partido que governa o país a nível nacional desde o fim do apartheid. Vide nota 11. 
Aliadas às conhecidas altas taxas de desemprego, que igualmente afetam desproporcionalmente a população black, ${ }^{11}$ a queda na taxa de casamento provoca, de acordo com esses autores que argumentam pela relação direta entre o aumento do desemprego e a queda das taxas matrimoniais, uma desestabilização das expectativas de gênero. Hickel (2015) sustenta que, em um clima de desemprego crônico, torna-se menos possível que um homem ganhe o suficiente para levantar tanto os recursos para o pagamento do lobolo, prestação matrimonial paga à família da noiva que garante a reprodução social legítima, quanto aqueles necessários para o estabelecimento de residência independente. Num contexto socioeconômico que dificulta certas trocas tradicionalmente realizadas para a efetivação das prestações matrimoniais, que outros laços afetivos e que outras trocas materiais vão perpassar relacionamentos entre homens e mulheres?

Tanto na antropologia quanto nas demais ciências sociais as produções acerca dos chamados relacionamentos intergeracionais transacionais foram e são marcadas pelas políticas de combate à epidemia de HIV/AIDS. ${ }^{12}$

Na tentativa de lidar com as altas taxas de contágio de HIV, especialmente entre jovens mulheres black, parcela da população entre a qual os índices têm especialmente aumentado, uma ampla gama de estudos focou na difundida existência de relacionamentos sexuais transacionais intergeracionais. Primariamente, esta literatura levanta questões acerca da natureza desigual desses relacionamentos e da vulnerabilidade das jovens mulheres a práticas sexuais arriscadas e/ou coercitivas (Tamara SHEFER; Anna STREBEL, 2013).

Relatórios de órgãos locais e internacionais que se debruçaram sobre a epidemia traçaram uma correlação entre tais relacionamentos transacionais, em especial os intergeracionais, e os aumentos dos índices de infecção entre mulheres black na África do Sul. Tais relatórios apontaram para os empecilhos na negociação do uso de preservativo, uma vez que mulheres estariam em posição de menos barganha. Entretanto, como parte da produção vem tentando evidenciar, trata-se de arranjos muito variados, cuja negociação é bastante mais complexa do que os relatórios parecem demonstrar, e de que os dados socioeconômicos sozinhos conseguem evidenciar.

Está bem documentado que, na África do Sul, bem como em outros lugares no continente, as relações afetivo-sexuais e de aliança se constituem e conformam redes de obrigações e dependências que se dão por meio dos intercâmbios de sexo, trabalho, afeto e ajuda material. Esse é um sistema de troca segundo o qual o ato de dar presentes ou dinheiro, de um homem a uma mulher, expressa e constitui um laço emocional e obriga a receptora a alguma forma de reciprocidade, usualmente sexual (Brady G'SELL, 2016). Suzanne LECLERC-MADLALA (2008) afirma que:

O sexo intergeracional [age-disparate sex], que supõe um elemento recíproco/transacional, é parte de um sistema de interdependência que é mantido por duas prescrições culturais interligadas e duradouras. Uma prescreve que homens redistribuam riqueza em escala apropriada à sua posição e que demonstrem amor, compromisso ou apreço pelo sexo através de doações materiais. A outra prescreve que as mulheres esperem receber uma compensação material por favores sexuais como validação de seu valor e como um sinal de amor, comprometimento ou apreço do parceiro. Para uma mulher, "fazer sexo de graça" tem um sentido em toda essa região [refere-se à África austral] de falta de dignidade e de amor próprio (p. 23).

A ênfase nas transações materiais nas relações interpessoais já foi apontada em outros países do continente (Robert LEVINE, 1973). O que essa nova produção deseja destacar é que não é necessariamente para alívio de pobreza que mulheres decidem iniciar esses relacionamentos, questionando assim todo um regime moral que se baseia numa "razão prática", para usar uma expressão de Marshall SAHLINS (2003), desconsiderando outros fatores envolvidos nessas relações (G'SELL, 2016; HUNTER, 2002; 2005; 2009; Carol E. KAUFMAN; Stavros E. STAVROU, 2004; LECLERCMADLALA, 2003; 2008; Sarah PUDIFIN; Shannon BOSCH, 2012; SHEFER et al., 2010; SHEFER; STREBEL, 2013; Kirsten STOEBENAU et al., 2011).

Esses trabalhos buscam ainda desafiar a noção de desamparo e vulnerabilidade das mulheres nas negociações por sexo seguro com homens mais velhos. Shefer e Strebel (2013) apontam exemplos que refletem o exercício de agência das jovens nas negociações dos termos de seus relacionamentos. Sua preferência por homens mais velhos, as autoras continuam, também é postulada ao condenarem a não confiabilidade dos homens de seu grupo de idade. Apesar de

\footnotetext{
1 Por conta dos altos índices de pobreza e desemprego entre a população black - os índices de desemprego são de $28 \%$ entre blacks e $5 \%$ entre whites (MORREL et al., 2012) - o acesso ao casamento é dificultado e a queda nas taxas de casamento que se observa desde os anos 1960 é mais dramática entre essa mesma população black (G'SELL, 2016). Em 2010, somente $25 \%$ das mulheres black eram casadas, em comparação com $60 \%$ das mulheres white. Em 2012, 69\% das crianças black viviam sem a figura paterna. Muitas vezes sendo a única fonte de renda, as mulheres são desproporcionalmente afetadas pelo desemprego (39\% mulheres para $22 \%$ para homens). Neste cenário, um caminho econômico independente para mulheres fica igualmente dificultado (HUNTER, 2012).

12 Para um paralelo na abordagem dessas questões em Moçambique e no Brasil, vide, nesta Seção Temática, o artigo de Carla BRAGA (2019).
} 
muito da mídia e do senso comum retratar sugar daddies como predatórios, Hunter (2012) afirma que frequentemente mulheres os veem como respeitáveis benfeitores e contrastam-nos favoravelmente a homens jovens, os últimos tipicamente desempregados. Em suas comunidades, o autor sustenta, os sugar daddies são raramente vistos como simplesmente "subornando" mulheres jovens em troca de sexo ao mesmo tempo que suas idades permitem que seus presentes sejam vistos mais como ajuda do que como suborno.

Relatos da importância do apoio emocional que essas figuras de homens mais velhos representam também apareceram nessa produção (SHEFER et al., 2010), além de demonstrações das variadas formas de intimidade emocional que esses relacionamentos envolvem (SHEFER; STREBEL, 2013). Sentirem-se amadas e desejadas também era apontado pelas jovens mulheres como esferas importantes desses relacionamentos (LECLERC-MADLALA, 2008).

Esse corpo de trabalho vem desestabilizando concepções simplistas e binárias de homens mais velhos como inevitáveis perpetradores de sexo desigual e mulheres jovens como vítimas necessárias que passivamente se engajam nessas trocas, apenas para alívio da pobreza. Enquanto a necessidade econômica é reconhecida como motivadora no envolvimento das mulheres, essas autoras e autores apontam para outros fatores que contribuem para o estabelecimento desses relacionamentos. Além de estarem inscritos em práticas e intercâmbios histórica e socialmente localizados (LECLERC-MADLALA, 2008; STOEBENAU et al., 2011), um fator de grande importância para o engajamento nesses arranjos parece ser, para além da já mencionada dimensão das trocas afetivas, a aspiração ao consumo de classes médias.

Para Hunter (2009), o consumo foi/é historicamente um importante marcador de status na África do Sul. Entretanto, segue o autor, no período pós-apartheid, publicitários nos meios midiáticos claramente aliaram o consumo a ideais de liberdade. A classe média, agora crescentemente diversa em termos de raça, relaciona-se afetivo-sexualmente de formas que vêm se transformando (ainda que de maneira majoritária e homogâmica em termos raciais), tomando espaços de lazer como shoppings, praias e restaurantes, lugares cuja presença era barrada para pessoas não whites durante o regime segregacionista. Assim, os sentidos de si mesmas das mulheres sul-africanas são moldados em relação ao aumento de riqueza das classes médias, que agora se torna multirracial (HUNTER, 2009; 2012).

O mesmo autor toma como exemplo a figura midiática da lt Girl para elaborar a respeito das formas como ela e a mídia transnacional ajudam a informar as feminilidades sul-africanas contemporâneas. A It Girl, como registrada pela versão sul-africana da famosa publicação de moda francesa Elle, é "sexy, corajosa, bem-sucedida [...] tem muito apelo sexual, é adorada e invejada em medidas iguais e, acima de tudo, possui o tipo de autoconfiança que não exige validação de ninguém" (HUNTER, 2012, p. 132).

Um trecho de outra revista feminina é representativo da forma como a manutenção de múltiplos parceiros por parte das mulheres tem sido retratada na mídia:

Várias mulheres muito inteligentes chegaram à conclusão de que, uma vez que seus namorados não estão sempre por perto para mentir para elas e dizer que as amam, não faz sentido não ter três cretinos, todos fazendo a mesma coisa, em momentos diferentes, é claro! Ao invés de sonhar (com) e ansiar por seu homem, você é constantemente regada de atenção por diferentes homens (HUNTER, 2012, p. 133).

Algumas mulheres reivindicam a categoria de "direito" para ressaltar que, num mundo 50/ 50 (o mundo da igualdade de gênero), elas agora têm o direito a ter múltiplos parceiros, assim como os homens (HUNTER, 2009; 2012; LECLERC-MADLALA, 2003; 2008). Hunter (2012) argumenta que não é necessariamente novo que mulheres demandem acesso a múltiplos parceiros, mas sim que elas o façam através da linguagem da igualdade de gênero e dos direitos universais em um contexto de desigualdades sociais sem precedentes.

Ao lado do "direito" ao acesso a parceiros múltiplos estão as demandas por "direito ao consumo". Hunter (2012) afirma que jovens mulheres das townships de KwaZulu-Natal, onde fez pesquisa de campo, também usavam a linguagem dos "direitos" para demandar acesso a bens de consumo. Nesses contextos, uma moral tradicional e noções calcadas em "direitos" liberais se intersectam para dar às mulheres um sentido de que elas deveriam se beneficiar desses bens. Uma intersecção que, de fato, é complexa e marcada por contradições e tensões.

Da maneira como a lt Girl é apresentada, portanto, ela é materialização de uma nova elite. A entrada neste segmento, ao menos segundo alguns discursos, depende agora não de critérios raciais, mas de classe (HUNTER, 2012).

Além do acesso ao consumo, outros marcadores de classe estão em jogo e vão informar a circulação dos sujeitos na África do Sul pós-apartheid. Como enfatizam Moutinho et al. (2010), a combinação entre língua e cor/raça é importante indicador de classe, que diferencia blacks vindos de lugares sociais diferentes. A autora demonstra, por exemplo, como dominar o idioma inglês significa manipular o mundo white. 
Moutinho et al. (2010) tratam das barreiras que a população jovem encontra para navegar nas relações afetivo-sexuais na "nova" África do Sul. A categoria acusatória Coconut, por exemplo, é usada contra jovens mulheres black que cruzam barreiras raciais e de classe, circulando por ambientes cosmopolitas e, até recentemente, exclusivamente whites. A autora sinaliza que tal termo pejorativo:

[E]videncia, portanto, os diferenciais de gênero e sexualidade articulados à raça e expõe o marcador de classe como um mecanismo que em parte possibilita um terreno comum de trocas à despeito das diferenças de raça, mas de outra parte ameaça a tradição e comportamentos anteriormente acordados (MOUTINHO et al., 2010, p. 167).

Como destaquei anteriormente, essas autoras e autores vêm enfrentando esse delicado campo, marcado por desigualdades de gênero, raça, classe e geração, desafiando os regimes morais correntes na tentativa de complexificar os debates sobre sexualidade e conjugalidade na África do Sul. Essa região do continente também esteve historicamente sob as lentes de gerações de antropólogas/os locais e estrangeiras/os que se debruçavam sobre, entre outras coisas, casamento e parentesco.

\section{Parentesco, casamento e afeto em contextos africanos}

A África Austral produziu, ao longo do século XX, extraordinárias etnografias e foi berço de parte de uma importante geração de antropólogas e antropólogos. Muitos destes estiveram, de maneira ou outra, associados à Escola de Manchester, em uma tradição que se inicia com Max Gluckman e Clyde Mitchell e que culmina, alguns argumentam, com as produções de Jean e John Comaroff (Ørnulf GULBRANDSEN, 2002).

Parte relevante dessas pesquisas se debruçou sobre o que se convencionou chamar de bridewealth, termo cunhado por Edward E. EVANS-PRITCHARD (1931), em um artigo intitulado "An alternative term for 'Bride-Price'". O termo se refere à prestação matrimonial que o noivo paga à família da noiva, amplamente praticada nessa região e fundamental entre grupos zulu e xhosa (Janet Hinson SHOPE, 2006; Dorrit POSEL; Stephanie RUDWICK, 2014), e que garante a paternidade dos filhos da união e, dessa forma, a reprodução social legítima (Max GLUCKMAN, 1982; Eileen Jensen KRIGE, 1977; KRIGE; John L. COMAROFF, 1981; Alfred RADCLIFFE-BROWN, 1982).

Gluckman (1982) apontou os "filhos ilegítimos" nascidos de mulheres a quem não foi pago o lobolo, como o bridewealth é chamado na região, como um "problema social" na Zululândia. A literatura clássica que versa sobre parentesco e prestações matrimoniais na antropologia africana tendeu a inquirir as regras e normas que balizam as alianças conjugais e não as práticas e as relações afetivas que envolvem as trocas matrimoniais (GLUCKMAN, 1982; Adam KUPER, 1982; RADCLIFFE-BROWN, 1982). Aina AZEVEDO (2015) defende que definições exclusivamente normativas do lobolo não trazem as dimensões "vividas" dessa prestação matrimonial, bem como suas negociações, contradições e transformações na contemporaneidade.

A estrutura das prestações matrimoniais pode ter consequências políticas, econômicas e sociais. Mesmo com a edição de The meaning of marriage payments por John L. COMAROFF (1980) e sua crítica à maneira como o estrutural-funcionalismo abordou a questão das prestações matrimoniais, a antropologia, de forma geral, vem ignorando os temas do amor e do matrimônio no continente nas últimas décadas (HUNTER, 2016; Lynn M. COLE; Jennifer THOMAS, 2009).

Um dos fatores que contribuiu para tanto foi a emergência da pandemia de HIV/AIDS. Hunter (2016) sustenta que nas últimas duas décadas os trabalhos tentaram conceitualizar e intervir (n)a sexualidade africana relacionada à indústria do HIV/AIDS.

Ainda que a antropologia tenha historicamente dado profunda atenção ao parentesco e ao casamento no continente, a disciplina não se deteve sobre o exame ou à teorização do amor e afeto. Cole e Thomas (2009) se perguntam sobre os motivos para tanto, uma vez que a antropologia tem uma ampla produção tratando de outros sentimentos, como inveja e raiva em África (Mary DOUGLAS, 1970; Grace Gredys HARRIS, 1978).

Notavelmente, Hunter (2009) indica que acadêmicos/as compreenderam a "facilidade" com a qual sexo é trocado em sociedades africanas a partir de duas narrativas. Uma explicação seria a de que o sexo está fora dos valores "tradicionais" africanos e por isso pode ser facilmente trocado. A outra hipótese é de que "forças da modernidade" agressivamente individualizaram, comodificaram e tornaram casuais as relações sexuais africanas. Esses pontos de vista dariam força à tendência de privilegiar os aspectos econômicos concernentes às relações íntimas em África em termos instrumentais e, portanto, antepostos ao amor.

Cole e Thomas (2009) recuperam as representações coloniais sobre o continente e ressaltam que, ao apresentarem a luxúria como onipresente e o amor ausente em África, e desse modo, situando os africanos moral e espiritualmente inadequados, essas perspectivas estabeleceram um conjunto de polêmicas racializadas que informaram as discussões e representações subsequentes da intimidade africana. Segundo Cole: 
Reduzir as relações íntimas ao sexo é problemático em toda parte. Entretanto, isso é particularmente relevante no caso da África devido à longa história de ocidentais se fazerem valer de argumentos a respeito da hipersexualidade para desumanizar africanos e justificar políticas degradantes. Estudos que investigam sexualidades africanas e ignoram o afeto contribuem para a persistente imagem ocidental da África como o "outro" do lluminismo europeu (COLE, 2009, p. 04).

Pode-se observar que, ao mesmo tempo em que a análise de relacionamentos intergeracionais transacionais na África do Sul remete a preocupações históricas do campo antropológico, ela também contribui grandemente para uma produção contemporânea que busca compreender configurações afetivas no continente, em meio a mudanças políticas, econômicas e sociais, com o cuidado de não confinar essas práticas ao período contemporâneo da globalização (THOMAS, 2009), nem entendê-las como meros produtos do "contato cultural" (Karin BARBER, 1997).

\section{"Mulheres lindas, homens ricos"}

Como dito anteriormente, nos últimos poucos anos a denominação sugar girl vem entrando no repertório brasileiro. Em aplicativos de relacionamento para smartphones, como o próprio Tinder, é possível encontrar perfis de jovens mulheres se autodenominando como tais, bem como perfis de sugar daddies oferecendo "mimos" e/ou dinheiro.

Muitas reportagens sobre o fenômeno foram publicadas nos últimos anos e todas elas trazem a plataforma Meu Patrocínio, cujo slogan é "mulheres lindas, homens ricos", como uma das responsáveis pela difusão do termo. Nesse site, sugar babies são descritas como mulheres que se preocupam com a aparência, gostam de cuidar de si e "sabem o preço da beleza". "Suas metas são claras", escrevem, uma sugar girl "quer crescer intelectual e profissionalmente e parar de se preocupar com contas" (MEU PATROCÍNIO, 2018).

Oferecem ainda listas de comportamento prescritos para ser uma sugar baby de sucesso. Seria preciso ter a mente aberta: "nada de hipocrisia ou comportamentos morais de séculos passados" (MEU PATROCÍNIO, 2018). No tratar com um sugar daddy, "nada de bombardeá-lo com perguntas pessoais ou falar de dinheiro na lata no primeiro dia" e "não perca tempo tentando mudá-lo" aparecem como dicas importantes.

Dê orgulho a ele de ter sua companhia. É necessário estar impecável ao sair com um Sugar Daddy - maquiagem, cabelo arrumado, roupa de bom gosto, cada detalhe conta. Lembrese de que ele quer uma mulher que desperte inveja nos outros homens (MEU PATROCÍNIO, 2018).

Na plataforma está colocado que sexo não é exigência, "nunca se sinta obrigada a fazer - é um relacionamento, e não uma transação comercial". "O sexo pode vir de forma natural e espontânea". A marcação da não exigência do sexo é fundamental, nesses contextos, para afastar o "estilo de vida sugar" do estigma da prostituição que paira sobre essas dinâmicas. Nos artigos saídos da grande mídia sobre o tema, muitos dos comentários de leitores iam nessa direção: tratar-se-ia de um novo nome para prostituição de luxo.

Jennifer LOBO (2017) é a jovem empresária por trás da plataforma Meu Patrocínio. Autora do livro Como Con\$ eguir um homem Rico: dicas para encontrar amor e dinheiro, Lobo não se mostra abalada com as críticas. A empresária diz que $85 \%$ dos usuários masculinos está em busca de relacionamentos duradouros, "sem joguinhos de sedução desnecessários!". "Querem um relacionamento para pagar a conta. Não querem uma mulher feminista, mas uma que goste que ele compre algo para ela" (In Litza MATTOS, 2019). Lobo argumenta:

O que é feminismo? É um movimento que propõe basicamente a igualdade de direitos entre homens e mulheres. Acontece que, por mais que se tenham queimado sutiãs, estamos na mesma desde os anos 1970. Então, como eu posso ter os mesmos acessos que o meu namorado, se eu ganho muito menos e gasto muito mais (com depilação, cabelo, unha, roupas e acessórios)? Aqui no Brasil, ainda tem a taxa rosa, que define um valor até $10 \%$ maior nos produtos destinados a mulheres. Aí, você aparece toda arrumada, e o cara não tem dinheiro para te pagar um puta jantar? É sacanagem, né? (In Paulo SAMPAIO, 2019).

O "estilo de vida sugar" é tratado como "moderno". No blog mantido pela empresa Estilosugar.com encontra-se um número de curtos textos tratando de moda, fitness, relacionamentos, saúde, além de dicas de beleza e relatos confessionais de sugar babies de sucesso. A plataforma internacional SeekingArrangement faz uso de discursos similares: "nós queremos que relacionamentos sejam equilibrados. Nós oferecemos a nossos membros um lugar para fazer isso acontecer" (SEEKINGARRANGEMENT, 2019). Descrevem a sugar girl de seu site como buscando relacionamentos modernos com valores tradicionais. Elas não querem "relacionamentos tradicionais monótonos prescritos pela sociedade - eles já não funcionam". Elas estão em busca de um "relacionamento moderno, um relacionamento diferente que combine com sua ambição e motivação [drive] - com um parceiro que possa fazer o papel de um provedor ou cavalheiro, sem colocar limitações despropositadas a seu crescimento pessoal". A isso chamam de "empowered dating" [namoro empoderado]. 


\section{Produção brasileira sobre intercâmbios de sexo, afeto e dinheiro: diálogos possíveis}

Na introdução à coletânea Sexualidade e Saberes: Convenções e Fronteiras, organizada por Adriana PISCITELLI, Maria Filomena GREGORI e Sérgio CARRARA (2004), as autoras retomam o conceito de "pânico sexual". Tratar-se-ia da ansiedade em torno de questões sexuais que:

Suscitaria conflitos no marco dos quais complexas agendas políticas acabaram utilizando o sexo à maneira de um veículo para a expressão de outras preocupações, como as relacionadas a uma suposta decadência moral ou desorganização social (p. 10).

Para essas autoras, a antropologia social, ao lado de outras ciências sociais e históricas, esforçou-se continuamente na direção de desnaturalizar a sexualidade. Entretanto, perguntam-se pelos limites dessa mesma desnaturalização e pelo alcance da "compreensão dos mecanismos políticos que perpassam as discussões sobre sexualidade quando lidamos com questões percebidas como requerendo urgente intervenção" (PISCITELLI; GREGORI; CARRARA, 2004, p. 12).

Este parece ser o caso para os contextos em que estão trabalhando pesquisadores/as na África do Sul e no Brasil. Durante o levantamento bibliográfico levado a cabo para a melhor compreensão do fenômeno de relacionamentos sugar na África do Sul, não pude me furtar em perceber que muitas das preocupações de autoras e autores sul-africanos que investigam relacionamentos entre blessers e jovens mulheres são similares àquelas do sólido corpo de estudos na antropologia brasileira sobre os mercados do sexo, afeto e casamento em um número de aspectos. Convergem, por exemplo, no que diz respeito à revisão de dicotomias e binarismos simplistas e no esforço de tratar com dignidade as escolhas dos sujeitos, mesmo que circunscritas por diferentes estruturas de poder (Thaddeus BLANCHETTE, 2011; MOUTINHO, 2004a; 2006; José Miguel Nieto OLIVAR, 2014; PISCITELLI, 201 1a; 201 1b; 2008; Ana Paula da SILVA; BLANCHETTE, 2005; 2010; SILVA, 2011 ; Júlio SIMÕES et al., 2010).

Diferentemente do contexto sul-africano, cuja produção é marcada pelo combate à epidemia de HIV/AIDS, a produção brasileira é permeada por "questões vinculadas ao turismo sexual, ao tráfico internacional de pessoas, aos casamentos associados aos mercados do sexo e à prostituição" (PISCITELLI, 2014, p. 162). Trata-se de uma produção permeada "pelo interesse em apoiar os direitos das trabalhadoras sexuais" e que "dialoga de maneira crítica com políticas que têm restringido o sexo comercial e limitado as mobilidades das pessoas envolvidas em trocas sexuais e econômicas, no país e no exterior" (PISCITELLI, 2014, p. 162).

Como argumenta Olivar (2014), a produção brasileira das últimas décadas se destaca pela quantidade e qualidade dos trabalhos, pela diversidade de abordagens, pelos diálogos em arenas políticas e pelas alianças com as militâncias. O autor continua:

Essa produção brasileira entendeu desde o início o intenso universo de derivas e devires, de misturas e entrecruzamentos que compõem este (e qualquer?) trabalho (PERLONGHER, 1987): sexualidades, tensões e produções de gênero, políticas públicas em diversas áreas, relações conjugais e familiares, ocupação da cidade e do tempo, estilos corporais, relações múltiplas com o dinheiro, afetos, entre outros. E entendeu que sem um olhar detalhado e próximo, sem uma escuta atenta e parceira, seria impossível compreender o trabalho (OLIVAR, 2014, p. 04).

As pesquisas que se dedicam aos intercâmbios entre amor/afeto e mercado/economia têm gerado importantes contribuições para repensar, no âmbito dos relacionamentos afetivo-sexuais, as barreiras que acoplam, de um lado, o dinheiro ao mercado do sexo e, de outro, o afeto às relações conjugais e familiares, como se as trocas econômicas pusessem em risco a pureza das relações afetivas (Viviana ZELIZER, 2009). Essa produção tem apontado para a arbitrariedade dessas barreiras e para a potencialidade de pensar as articulações entre as relações íntimas e as transações econômicas (Amalia CABEZAS, 2009; Christian GROES-GREEN, 2013; 2014; Kamala KEMPADOO, 2004; PISCITELLI, 2016; Valerio SIMONI, 2014; Felicity SCHAEFFER-GRABIEL, 2004; Jennifer JOHNSON-HANKS, 2007; Nicole CONSTABLE, 2003; 2009).

Nesse cenário, a produção brasileira apresenta, entretanto, características particulares. No lidar com as trocas materiais-afetivas-sexuais intergeracionais, a produção sul-africana tendeu a lidar com a noção de sexo transacional. Trata-se de uma noção que compreende os intercâmbios de dinheiro, presentes, afetos e sexo entre dois polos desiguais como parte de um conjunto mais amplo de trocas (G'SELL, 2016; HUNTER, 2002; LECLERC-MADLALA, 2008; STOEBENAU et al., 2011). Essa noção destaca fundamentalmente uma separação entre, de um lado, formas de intimidade afetivo-sexual com intercâmbios materiais e, de outro lado, a prostituição (HUNTER, 2002; PISCITELLI, 2014; STOEBENAU et al., 2011).

Na formulação de Mark Hunter, esse termo remete a trocas nas quais os participantes não se percebem como prostitutas e clientes e o intercâmbio de presentes por sexo é parte de um conjunto mais amplo de obrigações, que evocam reciprocidade, em relações desiguais, 
muitas vezes permeadas por afetos que remetem ao amor material, que pode surgir do coração e também ser promovido pelo dinheiro (PISCITELLI, 2014, p. 183).

Piscitelli argumenta que, nos trabalhos realizados no Brasil, essas trocas, inclusive a prostituição, extrapolam esses limites rígidos, permitindo antever como o sexo mercantilizado, o parentesco, a família, o lar, o trabalho, por exemplo, coexistem e habitam essas trocas (PISCITELLI, 2004; 2011a; 2014; 2016).

Claudia FONSECA (1996), em meados dos anos 1990, nos apresentou a figura do velho. Entre as mulheres "que batalham" de Porto Alegre, o velho representava um ideal. Além dos pagamentos regulares, ofereciam a elas presentes, viagens, eventualmente uma casa. Em troca, eles recebiam a impressão de ter acesso privilegiado a seus afetos.

Essa mesma autora nos auxiliava, na ocasião, a desconstruir o sentido de excepcionalidade inerente à categoria prostituta. Para Fonseca (1996), o mesmo velho também figurava no repertório e nas ambições das mulheres que não batalhavam de classes populares naqueles mesmos contextos. As noções de enriquecimento por casamento estavam amplamente presentes no imaginário dessas jovens.

Os mercados do casamento e do sexo ${ }^{13}$ também estão profundamente imbricados para Piscitelli (2011a; 2011 b; 2004; 2008). A figura do estrangeiro que também oferece "ajuda" foi mobilizada por suas interlocutoras trabalhadoras do sexo como forma de ascender socialmente, inclusive através do casamento com esses sujeitos.

Aqui, me volto novamente à noção de pânico sexual, e recoloco a questão trazida pelas autoras: como as ciências humanas leem as "convenções que compõem a normalização e criminalização de práticas que, embora envolvam questões relativas ao direito da livre expressão da sexualidade, provocam reações violentas, evocam a possibilidade de estarmos frente a uma nova onda de pânico sexual"? (PISCITELLI; GREGORI; CARRARA, 2004, p. 12).

Shefer e Strebel (2013) reivindicam que pesquisadores e profissionais da área interroguem suas próprias construções de gênero e as formas pelas quais podem estar reiterando binarismos na forma como levam a cabo suas pesquisas, interpretam seus dados e fazem recomendações.

Essa preocupação, presente em ambas as produções, nos remete novamente a Fassin (2008), em seu manifesto em direção a uma antropologia da moral. Refiro-me à necessidade de considerar os preceitos morais do/a próprio/a antropólogo/a como objeto de sua investigação. "Quanto mais estivermos conscientes e críticos de nossas próprias pressuposições e certezas morais [...]", ele argumenta, "mais seremos capazes de respeitar os campos epistemológicos e preservar os engajamentos políticos de nosso trabalho científico" (FASSIN, 2008, p. 338).

De alguma maneira atrelada a essa questão, um segundo ponto crítico para algumas autoras produzindo na África do Sul e no Brasil é a necessidade de prestar atenção ao perigo de reproduzir hierarquias globais no lidar com intercâmbios afetivos-sexuais-materiais. O olhar científico, especializado, sobre relacionamentos intergeracionais, em particular aqueles de natureza transacional, alertam Shefer e Strebel (2013), "pode estar servindo à função de 'tornar outro' ['othering'] comunidades pobres e africanas" (p. 6). Piscitelli (2016) adverte para riscos similares em uma produção de conhecimento "na qual apenas pessoas de alguns países 'pobres' e sexualizados são vinculadas a esses intercâmbios" (p. 07), em movimentos que tendem a "sexualizar e tornar exóticas as desigualdades" tomando primordialmente como referência, ao tratar do sexo transacional, camadas populares sem explorar essas dinâmicas em outras camadas sociais (PISCITELLI, 2014, p. 188).

Essas jovens, no Brasil e na África do Sul, se fazem valer de seus atributos para alcançar, entre outras coisas, acesso a bens de consumo, status e ascensão social. Enfrentando barreiras de gênero, classe e por vezes raça, não se encontram nas mesmas posições que seus velhos e seus blessers.

Como foi visto, não se trata de uma noção nova. Ainda assim, as mídias sociais e suas novas ferramentas de compartilhamento de imagens e aplicativos de relacionamento para smartphones vêm informando novas corporalidades exibíveis nas redes e outras linguagens através das quais enunciar desejos e objetivos. As noções do "estilo de vida sugar", da "It girl" ou do "namoro empoderado" nos fazem problematizar como essas plataformas estão auxiliando na criação de outros sentidos de si possíveis para essas jovens e discursivamente reconciliando noções antagônicas como a de "relacionamento moderno com valores tradicionais". Ao tomarem arranjos afetivo-sexuais e conjugais disponíveis, e narrarem-nos por vezes na lógica dos discursos de empoderamento pessoal e do feminismo, essas mulheres seguem na busca por "novos" velhos. Apenas em um trabalho atento, reflexivo e generoso, como nos exemplos da produção sul-africana e brasileira que neste artigo eu procurei esboçar, poderemos alcançar um olhar nuançado para a complexa paisagem contemporânea da sexualidade e conjugalidade. 13 Para os usos, diferenças, limites e potencialidades dos termos "mercados do sexo" e "economias sexuais", vide
Piscitelli (2016). 


\section{Referências}

ADAMS, Sarah. "Blessers: A new generation of South African sugar daddies". The South African, 21/ 05/2016. Disponível em https://www.thesouthafrican.com/news/blessers-a-new-generation-of-southafrican-sugar-daddies/. Acesso em 24/05/2018.

AZEVEDO, Aina. "'Se você quiser me lobolar' - considerações sobre o lobola na África do Sul contemporânea". Cadernos Pagu, Campinas, n. 45, p. 21-49, 2015.

BLANCHETTE, Thaddeus. “'Fariseus' e 'gringos bons': masculinidade e turismo sexual em Copacabana”. In: PISCITELLI, Adriana; ASSIS, Gláucia de Oliveira; OLIVAR, José Miguel Nieto (Orgs.). Gênero, sexo, afetos e dinheiro: mobilidades transnacionais envolvendo o Brasil. Campinas: EDUNICAMP/PAGU, 2011 . p. 57-103.

BARBER, Karin. "Introduction". In: BARBER, Karin. Readings in African Popular Culture. Bloomington: Indiana University Press, 1997. p. 01-12.

BOFFEY, Daniel. 'SUGAR Daddy' website targeting Belgian students faces legal fight. The Guardian, 26/09/201 7. Disponível em https://www.theguardian.com/world/2017/sep/26/sugar-daddy-websitetargeting-belgian-students-faces-legal-action-richmeetbeautiful. Acesso em 15/04/2018.

BRAGA, Carla. “'Machamba não é trabalho!': HIV/SIDA e Produção Agrícola no centro de Moçambique". Revista Estudos Feministas, v. 27, n. 3, 2019.

CABEZAS, Amalia. Economies of Desire: Sex and Tourism in Cuba and the Dominican Republic. Philadelphia: Temple University Press, 2009.

COLE, Lynn M. "Love, sex and the modern girl in 1930 Southern Africa". In: THOMAS, Jennifer; COLE, Lynn M. (Orgs.). Love in Africa. Chicago: University of Chicago Press, 2009. p. 31-57.

COLE, Lynn M.; THOMAS, Jennifer (Orgs.). Love in Africa. Chicago: University of Chicago Press, 2009. p. 109-134.

COMAROFF, John L. The meaning of Marriage Payments. Nova lorque: Academic Press, 1980.

CONSTABLE, Nicole. Romance on a global stage: pen pals, virtual ethnography, and "mail order" marriages. Berkeley: University of California Press, 2003.

CONSTABLE, Nicole. "The commodification of Intimacy: marriage, sex, and reproductive labour". Annual Review of Anthropology, v. 38, p. 49-64, outubro 2009.

CLUVER, Lucie et al. "Child-focused state cash transfers and adolescent risk of HIV infection in South Africa: a propensity-score-matched case-control study". The Lancet Global Health, v. 1, n. 6, p. 362$370,2013$.

CLUVER, Lucie et al. "Combination Social Protection for reducing HIV-Risk behavior among adolescents in South Africa". JAIDS, v. 72, n. 1, p. 96-104, 2016.

DOUGLAS, Mary. Witchcraft confessions and accusations. London: Tavistock, 1970.

EVANS-PRITCHARD, Edward E. "An Alternative Term for 'Bride-Price'”. Man, v. 31, p. 36-39, março 1931.

FASSIN, Didier. "Beyond good and evil?: questioning the anthropological discomfort with morals". Anthropological Theory, v. 8, n. 4, p. 333-344, 2008.

FONSECA, Claudia. "A dupla carreira da mulher prostituta". Revista Estudos Feministas, v. 4, n. 1, p. 07-33, 1996.

GLUCKMAN, Max. "Parentesco y Matrimonio entre los lozi de Rodesia del Norte y los zulúes de Natal". In: RADCLIFFE-BROWN, Alfred Reginald; DARYLL, Forde (Orgs.). Sistemas Africanos de Parentesco y Matrimonio. Barcelona: Anagrama, 1982. p. 185-233.

GROES-GREEN, Christian. "To put men in a bottle: eroticism, kinship, female power and transactional sex in Maputo, Mozambique". American Ethnologist, v. 40, n. 1, p. 102-11 1, 2013.

GROES-GREEN, Christian. "Journeys of Patronage: moral economies of transactional sex, kinship and female migration from Mozambique to Europe". Journal of the Royal Anthropological Institute, v. 20, n. 2, p. 237-255, 2014. 
G'SELL, Brady. "The 'Maintenance' of Family: Mediating Relationships in the South African Maintenance Court". Africa Today, v. 62, n. 3, p. 03-27, 2016.

GULBRANDSEN, Ørnulf. "Southern Africa”. In: BARNARD, Alan; SPENCER, Jonathan (Orgs.). Encyclopedia of Social and Cultural Anthropology. London: Routledge, 2002. p. 19-34.

HARRIS, Grace Gredys. Casting out anger: Religion among the Taita of Kenya. Cambridge: Cambridge University Press, 1978.

HICKEL, Jason. Democracy as death: the moral order of anti-liberal politics in South Africa. Oakland: University of California Press, 2015.

HUNTER, Mark. "The Materiality of Everyday Sex: thinking beyond 'prostitution'”. African Studies, v. 61, n. 1, p. 99-120, 2002.

HUNTER, Mark. "Cultural Politics and Masculinities: Multiple-Partners in Historical Perspective in KwaZulu-Natal”. Culture, Health \& Sexuality, v. 7, n. 4, p. 389-403, 2005.

HUNTER, Mark. "Providing Love: Sex and Exchange in Twentieth-Century South Africa". In: COLE, Jennifer; COLE, Lynn M. (Orgs.). Love in Africa. Chicago: University of Chicago Press, 2009. p. 135-156.

HUNTER, Mark. Love in times of AIDS: Inequality, gender and rights in South Africa. Bloomington: Indiana University Press, 2012.

HUNTER, Mark. "New Insights on Marriage and Africa”. Africa Today, v. 62, n. 3, p. vii-xv, 2016.

JOHNSON-HANKS, Jennifer. "Women on the market: marriage, consumption and the internet in urban Cameroon". American Ethnologist, v. 34, n. 4, p. 642-658, 2007.

KAUFMAN, Carol E.; STAVROU, Stavros E. "'Bus fare please': the economics of sex and gifts among young people in urban South Africa". Culture, Health \& Sexuality, v. 6, n. 5, p. 377-391, 2004.

KELSEY, Rick. "'A quarter of a million' UK students now using sugar daddies, according to app”. BBC Newsbeat, 08/02/2016. Disponível em http://www.bbc.co.uk/newsbeat/article/35521859/aquarter-of-a-million-uk-students-now-using-sugar-daddies-according-to-app. Acesso em 20/04/ 2018.

KEMPADOO, Kamala. Sexing the Caribbean: gender, race and sexual labour. Abington: Routledge, 2004.

KRIGE, Eileen Jensen. The Social System of the Zulu. Pietermaritzburg: Shuter \& Shooter, 1977.

KRIGE, Eileen Jensen; COMAROFF, John L. Essays on African Marriage in Southern Africa. Cape Town: Juta and Co., 1981.

KUPER, Adam. Wives for Cattle - Bridewealth and marriage in Southern Africa. Londres: Routledge \& Keagan Paul, 1982.

LAMBLE, Kate. "Fighting the curse of the blessers". BBC News, 21/05/2016. Disponível em https:// www.bbc.com/news/blogs-trending-36342561? ocid=socialflow_twitter. Acesso em 20/04/2018.

LECLERC-MADLALA, Suzanne. "Transactional Sex and the Pursuit of Modernity". Social Dynamics, v. 29, n. 2, p. 213-233, 2003.

LECLERC-MADLALA, Suzanne. "Age-disparate and intergenerational sex in southern Africa: the dynamics of hyper vulnerability". AIDS, v. 22, n. 4, p. 17-25, 2008.

LEVINE, Robert. "Patterns of personality in Africa". Ethos, v. 1, n. 2, p. 123-153, 1973.

LOBO, Jennifer. Como Con\$̦eguir um homem Rico: dicas para encontrar amor e dinheiro. São Paulo: Matrix, 2017.

LOPES, Pedro. "Deficiência como categoria do Sul Global: primeiras aproximações com a África do Sul”. Revista Estudos Feministas, v. 27, n. 3, 2019.

MATEBENI, Zethu. "Perspectivas do Sul sobre relações de gênero e sexualidades: uma intervenção queer". Revista de Antropologia, v. 0, n. 3, p. 26-44, 2017. 
MATTOS, Litza. "Minas é $3^{\circ}$ em clientes de site que 'patrocina' relacionamento aberto". O Tempo, 30/ 04/2019. Disponível em https://www.otempo.com.br/interessa/minas-\%C3\%A9-3\%C2\%BA-emclientes-de-site-que-patrocina-relacionamento-aberto-1 .21 75033. Acesso em 24/05/2019.

MORREL, Robert et al. "Hegemonic Masculinity/Masculinities in South Africa: Culture, Power, and Gender Politics". Men and Masculinities, v. 15, n. 1, p. 11-30, 2012.

MOUTINHO, Laura. Razão, "cor" e desejo: uma análise comparativa sobre relacionamentos afetivosexuais "inter-raciais" no Brasil e na África do Sul. São Paulo: EDUNESP, 2004a.

MOUTINHO, Laura. "'Raça', sexualidade e gênero na construção da identidade nacional: uma comparação entre Brasil e África do Sul”. Cadernos Pagu, Campinas, n. 23, p. 55-88, 2004b.

MOUTINHO, Laura. "Negociando com a adversidade: reflexões sobre 'raça', (homos)sexualidade e desigualdade social no Rio de Janeiro". Revista Estudos Feministas, Florianópolis, v. 14, n. 1, p. 103-116, 2006.

MOUTINHO, Laura et al. "Retóricas ambivalentes: ressentimentos e negociações em contextos de sociabilidade juvenil na Cidade do Cabo (África do Sul)". Cadernos Pagu, Campinas, n. 35, p. 139-176, 2010.

MOUTINHO, Laura; TRAJANO FILHO, Wilson; LOBO, Andréa. "Dossiê Olhares Cruzados para a África: Trânsitos e mediações - Algumas reflexões". Revista de Antropologia, São Paulo, v. 60, n. 3, p. 7-25, 2017.

MVUMVU, Zingisa. "Hey, ladies, don't take shortcuts by dating blessers: ANCYL". The Sunday Times, 31/07/2018. Disponível em https://www.timeslive.co.za/politics/2018-07-31-hey-ladies-dont-takeshortcuts-by-dating-blessers-ancyl/. Acesso em 24/05/2019.

NAKELI-DHLIWAYO, Kekeletso. "Blesser trend is a gilded cup of poison". The Citizen, 12/05/2016. Disponível em https://citizen.co.za/news/opinion/opinion-columns/1111275/blesser-poison-cupspiral/. Acesso em 24/05/2018.

MEU PATROCÍNIO. "O que é Sugar Baby - Saiba como ser uma". Meu Patrocínio, 2018. Disponível em https://www.meu

patrocinio.com/sejaumasugarbaby/?utm_source=googlecpc\&utm_campaign=google-cpcsugarbaby\&gclid=CjwKEAjw9MrlBRCr2LPek5-h8UOSJAD3jfhtSCv_V5aXm8YdIV1 qsjZ18c60An_gWf7pzYHz48uqhoCvyfw_wcB. Acesso em 04/04/2018.

OLIVAR, José Miguel Nieto. "Adolescentes e Jovens nos Mercados do Sexo na Tríplice Fronteira Brasil, Peru, Colômbia: Três Experiências, um Tour de force e Algumas Reflexões". Revista Artemis, v. 18, n. 1, p. 87-102, 2014.

PISCITELLI, Adriana. "Entre a praia de Iracema e a União Européia: turismo sexual internacional e migração feminina”. In: PISCITELLI, Adriana; GREGORI, Maria Filomena; CARRARA, Sérgio (Orgs.). Sexualidade e saberes: convenções e fronteiras. Rio de Janeiro: Garamond, 2004. p. 283-318.

PISCITELLI, Adriana. "Interseccionalidades, categorias de articulação e experiências de migrantes brasileiras". Sociedade e Cultura, v. 11, n. 2, p. 263-275, 2008.

PISCITELLI, Adriana. "Actuar la brasileñidad? Tránsitos a partir del mercado del sexo". Etnográfica, v. 15, n. 1, p. 5-29, 2011 a.

PISCITELLI, Adriana. "Amor, apego e interesse: trocas sexuais, econômicas e afetivas em cenários transnacionais". In: PISCITELLI, Adriana; ASSIS, Gláucia de Oliveira; OLIVAR, José Miguel Nieto (Orgs.). Gênero, sexo, afetos e dinheiro: mobilidades transnacionais envolvendo o Brasil. Campinas: EDUNICAMP/PAGU, 201 1b. p. 537-587.

PISCITELLI, Adriana. "Violências e afetos: intercâmbios sexuais e econômicos na (recente) produção antropológica realizada no Brasil". Cadernos Pagu, Campinas, n. 42, p. 159-199, 2014.

PISCITELLI, Adriana. "Economias sexuais, amor e tráfico de pessoas - novas questões conceituais". Cadernos Pagu, Campinas, n. 47, 2016. Disponível em http://www.scielo.br/scielo.php?script=sci_ arttext\&pid=S0104-83332016000200401 \&lng=en\&nrm=iso. Acesso em 20/02/201 8.

PISCITELLI, Adriana; GREGORI, Maria Filomena; CARRARA, Sérgio. "Apresentação". In: PISCITELLI, Adriana; GREGORI, Maria Filomena; CARRARA, Sérgio (Orgs.). Sexualidade e saberes: convenções 
e fronteiras. Rio de Janeiro: Garamond, 2004. p. 9-35.

POSEL, Dorrit; RUDWICK, Stephanie. "Marriage and Bridewealth (ilobolo) in contemporary Zulu society". African Studies Review, v. 57, n. 2, p. 51-72, 2014.

PUDIFIN, Sarah; BOSCH, Shannon. "Demographic and social factors influencing public opinion on prostitution: an exploratory study in Kwazulu-Natal province, South Africa". P.E.R., v. 15, n. 4, p. 01-42, 2012.

RADCLIFFE-BROWN, Alfred. "Introduccion". In: RADCLIFFE-BROWN, Alfred Reginald; DARYLL, Forde (Orgs.). Sistemas Africanos de Parentesco y Matrimonio. Barcelona: Anagrama, 1982. p. 11-97.

SAHLINS, Marshall. Cultura e Razão Prática. São Paulo: Jorge Zahar, 2003.

SAMPAIO, Paulo. "'Escola da riqueza': curso no Brasil ensina como fisgar marido milionário". Universa, 15/02/2019. Disponível em https://paulosampaio.blogosfera.uol.com.br/2019/02/15/curso-sepropoe-a-ensinar-mocas-ambiciosas-a-galgar-mundo-dos-homens-ricos/?dos-homens-ricos/. Acesso em 24/05/2019.

SAPA. "Aids in South Africa: grants fight 'sugar daddy' Peril”. The Citizen, 23/1 1/2013. Disponível em https://citizen.co.za/news/south-africa/90559/aids-south-africa-grants-fight-sugar-daddy-peril/. Acesso em 24/05/2018.

SAVIDES, Dave. "Activist gets 'blesser' threats". The Citizen, 12/08/2016. Disponível em https:// citizen.co.za/news/south-africa/12491 14/activist-gets-blesser-threats/. Acesso em 24/05/2019.

SCHAEFFER-GRABIEL, Felicity. "Cyberbrides and Global Imaginaries: Mexican women's turn from the national to the foreign". Space and Culture, v. 7, n. 1, p. 33-48, 2004.

SEEKINGARRANGEMENT. "Home Page". Sobre nós, 2019. Disponível em https://www.seeking.com/pt/ about-us. Acesso em 05/05/2019.

SHAMASE, Nelly. "Damned by the 'blessers". Mail \& Guardian, 11/03/2016. Disponível em https:// mg.co.za/article/2016-03-10-damned-bythe-blessers.

SHEFER, Tamara; STREBEL, Anna. "Deconstructing the 'sugar daddy': A critical review of the constructions of men in intergenerational sexual relationships in South Africa". Agenda, v. 26, n. 4, p. 57-63, 2013.

SHEFER, Tamara et al. "South African teachers' responses to teenage pregnancy and teenage mothers in schools". Culture, Health and Sexuality, v. 12, n. 8, p. 871-883, 2010.

SHOPE, Janet Hinson. "'Lobola is here to stay': rural black women and the contradictory meanings of lobolo is post-apartheid South Africa". Agenda: empowering women for gender equity, n. 68, p. 6472, 2006.

SILVA, Ana Paula da. "'Cosmopolitismo tropical': uma análise preliminar do turismo sexual internacional em São Paulo". In: PISCITELLI, Adriana; ASSIS, Gláucia de Oliveira; OLIVAR, José Miguel Nieto (Orgs.). Gênero, sexo, afetos e dinheiro: mobilidades transnacionais envolvendo o Brasil. Campinas: EDUNICAMP/PAGU, 2011. p. 103-140.

SILVA, Ana Paula da; BLANCHETTE, Thaddeus. “'Nossa Senhora da Help': sexo, turismo e deslocamento transnacional em Copacabana". Cadernos Pagu, Campinas, n. 25, p. 249-280, 2005.

SILVA, Ana Paula da; BLANCHETTE, Thaddeus. “'A mistura clássica': miscigenação e o apelo do Rio de Janeiro como destino para o turismo sexual". Bagoas, n. 5, p. 221-244, 2010.

SIMÕES, Júlio et al. "Jeitos de corpo: cor/raça, gênero, sexualidade e sociabilidade juvenil no centro de São Paulo". Cadernos Pagu, Campinas, n. 35, p. 37-78, 2010.

SIMONI, Valerio. "From tourist to person: the value of intimacy in touristic Cuba". Journal of Tourism and Cultural Change, v. 12, n. 3, p. 280-292, 2014.

STOEBENAU, Kirsten et al. "More than just talk: the framing of transactional sex and its implications for vulnerability to HIV in Lesotho, Madagascar and South Africa". Globalization and Health, v. 34, n. 7, p. $01-15,2011$.

THOMAS, Jennifer. "Love, Money and Economies of Intimacy in Tamatave, Madagascar". In: THOMAS, Jennifer; COLE, Lynn M. (Orgs.). Love in Africa. Chicago: University of Chicago Press, 2009. p. 109- 
134.

THE SUNDAY TIMES. Looking for a sugar daddy: Money hungry women trawl the Internet - to SA's shame, 12/07/2018. Disponível em https://www.timeslive.co.za/news/sci-tech/2018-07-12-moneyhungry-women-trawling-the-internet-to-south-africas-shame/. Acesso em 24/05/2019.

WA AFRIKA, Mzilikazi. "Ramaphosa speaks out: I'm not a blesser, but I did have an affair". The Sunday Times, 03/07/2017. Disponível em https://www.timeslive.co.za/sunday-times/news/201 7-0902-ramaphosa-speaks-out-im-not-a-blesser-but-i-did-have-an-affair/. Acesso em 22/03/2018.

ZELIZER, Viviana. "Dinheiro, poder e sexo". Cadernos Pagu, Campinas, n. 32, p. 135-157, 2009.

Thais Henriques Tiriba (thaistiriba@gmail.com) é doutoranda no Programa de PósGraduação em Antropologia Social (PPGAS) da Universidade de São Paulo. Mestra em Antropologia Social pela mesma instituição. Pesquisadora do Núcleo de Estudos sobre Marcadores Sociais da Diferença (NUMAS). Desenvolve pesquisas na área de relações de gênero, relações raciais, mercados matrimoniais transnacionais e conjugalidades contemporâneas no Brasil, Alemanha e África do Sul.

\section{COMO CITAR ESSE ARTIGO DE ACORDO COM AS NORMAS DA REVISTA}

TIRIBA, Thais Henriques. "Sugar relationships: sexo, afeto e consumo na África do Sul e no Brasil". Revista Estudos Feministas, Florianópolis, v. 27, n. 3, e66921, 2019.

\section{CONTRIBUIÇÃO DE AUTORIA}

Não se aplica.

\section{FINANCIAMENTO}

Edital PROÁFRICA CNPq. Fundação de Amparo à Pesquisa do Estado de São Paulo (FAPESP)

\section{CONSENTIMENTO DE USO DE IMAGEM}

Não se aplica.

APROVAÇÃO DE COMITÊ DE ÉTICA EM PESQUISA

Não se aplica.

\section{CONFLITO DE INTERESSES}

Não se aplica.

\section{LICENÇA DE USO}

Este artigo está licenciado sob a Licença Creative Commons CC-BY International. Com essa licença você pode compartilhar, adaptar, criar para qualquer fim, desde que atribua a autoria da obra.

\section{HISTÓRICO}

Recebido em 06/08/2019

Aprovado em 16/08/2019 